\title{
Cardiac arrhythmias during acute exacerbations of chronic airflow limitation: effect of fall in plasma potassium concentration induced by nebulised beta ${ }_{2}$-agonist therapy
}

\author{
Richard Lim, Martin J. Walshaw, Stephen Saltissi and Charles R.K. Hind
}

Department of Medicine, Royal Liverpool Hospital, University of Liverpool, Liverpool L7 8XP, UK.

\begin{abstract}
Summary: The effect on cardiac rhythm of the fall in plasma potassium concentration induced by nebulised beta ${ }_{2}$-agonist therapy was studied in 20 patients admitted to hospital with an acute exacerbation of their reversible chronic airflow limitation. Arrhythmias considered serious or potentially lifethreatening were recorded in 13 patients (65\%). However, there was no significant increase in these arrhythmias in the hour following administration of nebulised beta ${ }_{2}$-agonist despite a significant fall in plasma potassium concentration during this period.
\end{abstract}

\section{Introduction}

Physicians practising respiratory medicine are concerned by the apparent recent increase in asthma mortality. ${ }^{1}$ Whilst the majority of such deaths are likely to be due to undertreatment, ${ }^{2,3}$ undue reliance on, and consequent overtreatment with, bronchodilators has also been blamed. For example, a recent study of 75 deaths in asthmatic patients using home nebulisers reported that $16-30 \%$ delayed seeking help because of over-reliance on high-dose beta ${ }_{2}$ agonists. ${ }^{4}$ The exact mechanism of death in such cases is unknown, but has been postulated to be due to fatal cardiac arrhythmias induced by hypoxia. ${ }^{3}$ An alternative hypothesis is that inhalation of high-dose beta ${ }_{2}-$ agonists may itself induce fatal arrhythmias perhaps secondary to beta ${ }_{2}$-agonist-induced hypokalaemia. ${ }^{5}$ Theoretically this hypokalaemia may be further aggravated by the acute stress of the illness, ${ }^{6}$ and by concomitant corticosteroid ${ }^{7}$ or theophylline therapy. ${ }^{8}$

Certainly nebulised beta ${ }_{2}$-agonists have been shown to induce hypokalaemia in normal volunteers, ${ }^{9}$ as have inhaled, subcutaneous and intravenous beta ${ }_{2}$-agonists in stable or acutely ill asthmatics. ${ }^{10-12}$ However, the clinical relevance of such drug-induced hypokalaemia, and in particular its potential effect on cardiac rhythm, has not previously been investigated in patients receiving nebulised beta $a_{2}$-agonist therapy during their acute respiratory illness. We therefore prospectively studied the effect of such treatment on cardiac rhythm in consecutive patients admitted to hospital with an acute exacerbation of their reversible chronic airflow limitation.

Correspondence: C.R.K. Hind, M.D.

Accepted: 15 February 1989

\section{Patients and methods}

\section{Patients}

Twenty consecutive patients admitted to hospital with an acute exacerbation of their chronic airflow limitation (CAL) were studied (11 male, mean age 67, range 29-82 years). All had CAL which was reversible as defined by variability in forced expiratory volume in one second $\left(\mathrm{FEV}_{1}\right)$ (18 patients) or peak expiratory flow rate (PEFR) (20 patients) of $>20 \%$ during their hospital stay. ${ }^{13}$ Five patients had pathological $Q$ waves on the baseline electrocardiogram (ECG) indicating previous myocardial infarction. All patients were in sinus rhythm, and none was taking oral beta ${ }_{2}$-agonist, beta-blocker, digitalis or anti-arrhythmic therapy.

On admission, each patient received either salbutamol or terbutaline ( $5 \mathrm{mg}$ four times a day) via an air-driven Bard home nebuliser (Bard Ltd, Sunderland SR4 9EW) which was continued throughout the period of the study. None received intravenous corticosteroid or theophylline therapy.

\section{Methods}

A continuous 24-hour ECG was performed on each patient on both the day of admission (acute record), and on the day before discharge (convalescent record). During each recording, symptom diaries were kept by patients who also noted the times of starting each administration of nebulised beta ${ }_{2}$-agonist.

Recordings were made using the Oxford Medilog 4000-II recorder (Oxford Medical Ltd, Abingdon OX14 1BZ) and played back on the Medilog MP4500 
computer system with the facility to search, scan and verify or edit. Full disclosure of each recording enabled counting of episodes of ventricular tachycardia, couplets, supraventricular tachycardia and atrial fibrillation.

Recorded arrhythmias were classified into two groups ('serious' and 'other') on the basis of their life-threatening potential. ${ }^{14}$ 'Serious' arrhythmias comprised ventricular tachycardia $(>3$ successive ventricular ectopics, rate $>110$ beats $/ \mathrm{min}$ ), ventricular couplets, and frequent ventricular ectopics ( $>30$ per hour over 24 hours). 'Other' arrhythmias, by comparison benign, included infrequent ventricular ectopics, supraventricular ectopics, paroxysmal supraventricular tachycardia and atrial fibrillation. The hourly frequency of each arrhythmia was noted for the four one-hour periods immediately following each nebulisation. The mean hourly frequency of each arrhythmia during this post-nebulisation period was then calculated and compared with that for the remaining 20 hours of each 24-hour recording period.

On admission to hospital (acute illness), the plasma potassium concentration was measured in each patient immediately before the first nebulisation of beta ${ }_{2}$ agonist and then $\mathbf{4 5}$ minutes later. Serum theophylline level and arterial blood gas tensions at the time of the first plasma potassium sample were also measured. In addition, serial measurements of PEFR, and FEV and forced vital capacity (FVC) were made just before, and 60 minutes following each nebulisation. Following clinical recovery, all these investigations were then repeated on the day before the patient's discharge from hospital (convalescent period).

Data analysis was performed using paired and unpaired Student's $t$ tests (two-tailed). Correlation was assessed by the least squares method.

\section{Results}

Table I summarises the patients' clinical and laboratory data at the time of their admission (acute $\varrho$

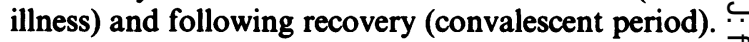

There was a significant fall in plasma potassium $\overrightarrow{\vec{F}}$ concentration following the first nebulisation during $\overrightarrow{0}$ both the acute illness [mean $0.30 \mathrm{mmol} / \mathrm{l}$, standard $\frac{\mathrm{C}}{\circ}$ deviation (s.d.) $0.41, P<0.005,95 \%$ confidence inter- $\overline{\frac{\sigma}{\sigma}}$ val (CI) 0.11-0.49] and convalescent period (mean $\overrightarrow{\mathbb{D}}$ $0.16 \mathrm{mmol} / 1$, s.d. $0.29, P<0.025, \mathrm{CI} 0.03-0.29$ ). This fall during the acute illness correlated significantly $\omega$ with the serum theophylline level $(r=0.64, \vec{O}$ $P<0.025$ ), but not with the severity of the acute $\overrightarrow{ }$ illness as defined by heart rate, PEFR, FEV 1 or the $\vec{\omega}$ degree of hypoxaemia.

The number of patients with potentially lifethreatening ('serious') arrhythmias was the same during both the acute illness and the convalescent period of $(13 / 20,65 \%)$, as were the mean hourly frequencies of oे $^{\circ}$ these arrhythmias. Frequent ventricular ectopics were more common in patients with previous myocardial $\overrightarrow{0}$ infarction $(80 \%)$ than in those without $(40 \%)$. 응 Similarly, the incidence of ventricular couplets and tachycardia was higher in patients with previous $\subseteq$ myocardial infarction [mean number of episodes $194 \stackrel{\bigodot}{\gtrless}$ (s.d. 282) vs 3 (s.d. 4) $(P<0.02)$ ]. These differences $\overrightarrow{0}$ were significant only during the convalescent perio $\infty$ However, there was no significant correlation betwee the mean hourly frequency of such arrhythmias and patient age, severity of the acute illness (as defined by heart rate, PEFR, $\mathrm{FEV}_{1}$, arterial $\mathrm{pH}$ and $\mathrm{PO}_{2}$ ), or initial plasma potassium or serum theophylline level. Furthermore, there was no significant increase in the frequencies of 'serious' arrhythmias during the $\overrightarrow{\overrightarrow{0}}$ 4 one-hour periods immediately following nebulisa-

Table I Clinical and laboratory variables

\begin{tabular}{|c|c|c|c|c|c|}
\hline & \multicolumn{2}{|c|}{ Acute illness } & \multicolumn{2}{|c|}{ Convalescent period } & \multirow[b]{2}{*}{$P$} \\
\hline & mean & (range) & mean & (range) & \\
\hline Heart rate (beats/min) & 94 & $(71-114)$ & 93 & $(66-124)$ & NS \\
\hline PEFR (litres/min) & 125 & $(<60-230)$ & 170 & $(70-440)$ & $<0.001$ \\
\hline FEV 1 (litres) & 0.75 & $(0.30-2.00)$ & 0.95 & $(0.40-3.30)$ & $<0.01$ \\
\hline Plasma K+ $\mathrm{K}^{+}(\mathrm{mmol} / \mathrm{l})$ & 4.05 & $(2.90-4.90)$ & 4.13 & $(3.50-4.60)$ & NS \\
\hline Arterial pH & 7.43 & $(7.34-7.49)$ & 7.43 & $(7.33-7.52)$ & NS \\
\hline Arterial $\mathrm{Po}_{2}(\mathrm{kPa})$ & 8.5 & $(6.3-12.5)$ & 9.3 & $(7.3-12.5)$ & $<0.005$ \\
\hline $\begin{array}{l}\text { Serum theophylline } \\
\text { (normal } 55-110 \mu \mathrm{mol} / \mathrm{l} \text { ) }\end{array}$ & 64 & $(<14-159 ; n=13)$ & 61 & $(<14-90 ; n=12)$ & NS \\
\hline \multicolumn{6}{|l|}{ Therapy: } \\
\hline oral steroids & \multirow{5}{*}{\multicolumn{2}{|c|}{$\begin{array}{r}8 \text { patients } \\
7 \text { patients } \\
13 \text { patients } \\
6 \text { patients } \\
11 \text { patients }\end{array}$}} & \multirow{5}{*}{\multicolumn{2}{|c|}{$\begin{array}{r}5 \text { patients } \\
10 \text { patients } \\
12 \text { patients } \\
6 \text { patients } \\
6 \text { patients }\end{array}$}} & \\
\hline inhaled steroids & & & & & \\
\hline oral theophylline & & & & & \\
\hline diuretic & & & & & \\
\hline potassium supplements & & & & & \\
\hline
\end{tabular}

NS - not significant. 
tion of beta $a_{2}$-agonists, during either the acute illness or the convalescent period (Table II). In particular, there was no significant increase in the frequencies of these arrhythmias during the hour following the first nebulisation when the plasma potassium concentration was noted to fall significantly.

Though no difference was found between the acute and convalescent records in the number of patients with other more benign arrhythmias, the hourly frequency of supraventricular ectopics was significantly higher during the acute illness [mean 92 , (s.d. 146) vs 41 (s.d. 87) $(P<0.02)$ ]. Furthermore this hourly frequency was significantly higher immediately following nebulisation of beta ${ }_{2}$-agonists during the acute illness (Table II).

\section{Discussion}

Though not all were pure asthmatics, the patients studied here all had reversible chronic airflow limitation for which therapy with high-dose beta ${ }_{2}$-agonists via a home nebuliser may be given. ${ }^{15}$ In addition these patients have a higher incidence of life-threatening arrhythmias than younger asthmatics, because of the likelihood of coexistent coronary artery disease secondary to age and cigarette smoking. ${ }^{16}$ Furthermore, such patients are known to be at risk of sudden death. ${ }^{3,17}$ It is therefore reassuring that this study found no increase in potentially life-threatening arrhythmias following the use of nebulised beta ${ }_{2}$-agonists during these patients' acute respiratory illness. This lack of any increase was despite the significant fall in plasma potassium concentration demonstrated in these patients. Although supraventricular ectopics did occur more frequently in the hour following nebuliser use, they are considered to be benign ${ }^{18}$ and do not herald serious or life-threatening arrhythmias. ${ }^{14}$

The dose of nebulised beta $a_{2}$-agonists used in this study $(20 \mathrm{mg} /$ day $)$ is the standard daily dose recommended by the manufacturers. ${ }^{19}$ Furthermore, surveys of domiciliary nebuliser use during acute exacerbations (from which the patient survived or later died) have shown that this daily dose is rarely exceeded by the patients. ${ }^{4,15}$ Our results suggest that provided standard doses of beta ${ }_{2}$-agonists are given no more than 6 hourly, the use of air-driven home nebulisers does not seem to be associated with an increased risk of potentially life-threatening arrhythmias, and it would seem unlikely that this therapy contributes significantly to asthma mortality. At the same time, this study provides further support for the theory that the vast majority of deaths in this group of patients are due to undertreatment rather than overtreatment of their acute exacerbation.

\section{Acknowledgements}

We thank Barbara Lea and the technicians in the Cardiorespiratory Department, Royal Liverpool Hospital for their expert assistance, and Astra Pharmaceuticals and Allen \& Hanburys Ltd for financial support.

Table II Mean hourly frequency of arrhythmias (s.d.)

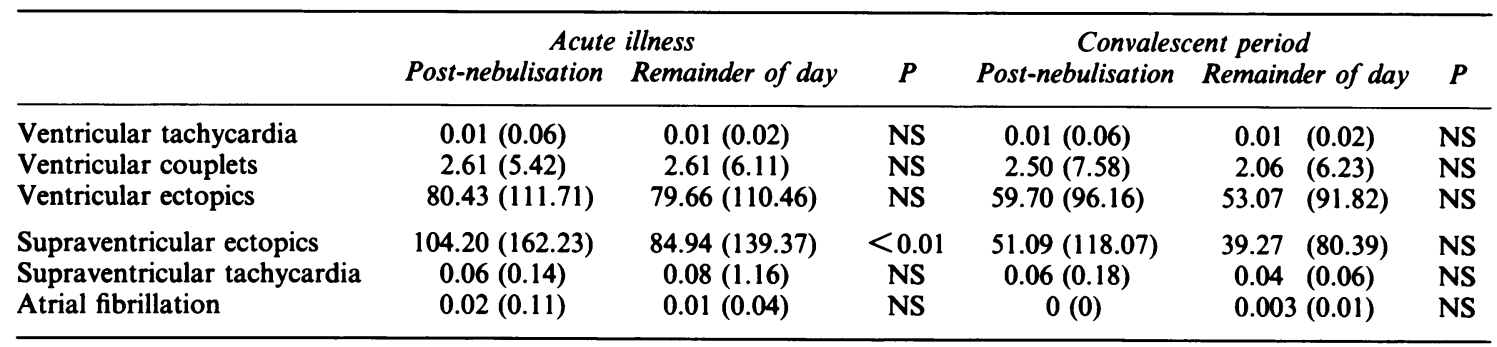

NS - not significant.

\section{References}

1. Burney, P.G.J. Asthma mortality in England and Wales: evidence for a further increase, 1974-84. Lancet 1986, ii: 323-326.

2. British Thoracic Association. Death from asthma in two regions of England. $\mathrm{Br} \mathrm{Med} J$ 1982, 285: 1251-1253.

3. Benatar, S.R. Fatal asthma. N Engl J Med 1986, 314: $423-429$.
4. Sears, M.R., Rea, H.H., Fenwick, J. et al. 75 deaths in asthmatics prescribed home nebulisers. Br Med J 1987, 294: 477-480.

5. Smith, S.R. \& Kendall, M.J. Metabolic responses to beta $_{2}$ stimulants. $J R$ Coll Physicians Lond 1984, 18: 190-194. 
6. Brown, M.J., Brown, D.C. \& Murphy, M.B. Hypokalaemia from beta ${ }_{2}$-receptor stimulation by circulating epinephrine. $N$ Engl J Med 1983, 309: 1414-1419.

7. Cochrane, G.M. Systemic steroids in asthma. In: Clark, T.J.H. (ed.) Steroids in Asthma. A reappraisal in the light of inhalation therapy. ADIS Press, Auckland, 1983, pp. $103-120$.

8. Addis, G.J., Whyte, K.F. \& Reid, J.L. The effects of steady state oral theophylline on catecholamine kinetics and adrenaline-induced hypokalaemia. In: TurnerWarwick, M., Levy, J. (eds) New Perspectives in Theophylline Therapy. Royal Society of Medicine, London, 1984, pp. 241-246.

9. Smith, S.R., Ryder, C., Kendall, M.J. \& Holder, R. Cardiovascular and biochemical responses to nebulised salbutamol in normal subjects. Br J Clin Pharmacol 1984, 18: $641-644$.

10. Nogrady, S.G., Hartley, J.P.R. \& Seaton, A. Metabolic effects of intravenous salbutamol in the course of acute severe asthma. Thorax 1977, 32: 559-562.

11. Haalboom, J.R.E., Deenstra, M. \& Struyvenberg, A. Hypokalaemia induced by inhalation of fenoterol. Lancet 1985 , i: $1125-1127$.

12. Kung, M., White, J.R. \& Burki, N.K. The effect of subcutaneously administered terbutaline on serum potassium in asymptomatic adult asthmatics. Am Rev Respir Dis 1984, 129: 339-342.
13. Benson, M.K. Diseases of the airways. In: Weatherall, D.J., Ledingham, J.G.G. \& Warrell, D.A. (eds) Oxford Textbook of Medicine. Oxford University Press, Oxford, 1983, pp. 15.60-15.71.

14. Pratt, G.M., Francis, M.J., Luck, J.C., Wyndham, C.R., Miller, R.R. \& Quinones, M.A. Analysis of ambulatory electrocardiograms in 15 patients during spontaneous ventricular fibrillation with special reference to preceding arrhythmic events. J Am Coll Cardiol 1983, 2: 789-797.

15. Laroche, C.M., Harries, A.V.K., Newton, R.C.F. \& Britton, M.G. Domiciliary nebulisers in asthma: a district survey. $\mathrm{Br}$ Med $J$ 1985, 290: 1611-1613.

16. Brashear, R.E. Arrhythmias in patients with chronic obstructive pulmonary disease. Med Clin N Am 1984, 68: 969-981.

17. Burrows, B. \& Earle, R.H. Course and prognosis of chronic obstructive lung disease: a prospective study of 200 patients. $N$ Engl J Med 1969, 280: 397-404.

18. Chiang, B.N., Perlmann, L.V., Ostrander, L.D. JR. \& Epstein, F.H. Relationship of premature systoles to coronary disease and sudden death in the Tecumseh epidemiologic study. Ann Intern Med 1969, 70: 1159-1166.

19. British National Formulary No. 16. British Medical Association and The Pharmaceutical Press, London, 1988, pp. 114-116. 